\title{
Proteomic studies of arbuscular mycorrhizal associations*
}

\author{
Manuel Sebastián Rebollo Couto ${ }^{1 \#}$, Paulo Emilio Lovato ${ }^{2}$, Daniel Wipf ${ }^{3}$, Eliane Dumas-Gaudot ${ }^{3}$ \\ ${ }^{1}$ Centro de Biologia Molecular Estrutural, Departamento de Bioquímica, CCB, Universidade Federal de Santa Catarina, Florianópolis, \\ Brazil \\ ${ }^{2}$ Departamento de Engenharia Rural, CCA, Universidade Federal de Santa Catarina, Florianópolis, Brazil \\ ${ }^{3}$ UMR INRA 1347/Agrosup/U Bourgogne Agroecology, ERL IPM 6300 CNRS, Dijon, France

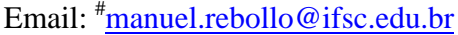

Received 24 October 2012; revised 24 November 2012; accepted 15 December 2012

\begin{abstract}
Arbuscular mycorrhizal (AM) fungi are soil-borne microorganisms forming mutualistic associations with the vast majority of land plants, including most agricultural relevant crops. In this association the plant provides the fungus with plant photosynthates allowing it to complete its life cycle, while the fungus provides the plant with mineral nutrients, mainly phosphorus and can also help the plant to tolerate biotic and abiotic stresses. In regard to these benefits there is growing interest on the use of AM fungi to improve productivity and sustainability in agricultural systems. AM fungi and their interactions with plants have been extensively studied using proteomic techniques, but some difficulties have been faced. 1) Little is known about the AM fungal typical protein repertoire because it is currently impossible to grow AM fungi in pure axenic cultures; 2) Plant tissues often contain high amounts of interfering substances that make protein extraction for the study of AM interactions a difficult procedure; 3) Most nutrient exchanges between AM fungi and their host plants involve participation of membrane proteins, still poorly resolved in most separation techniques. Finally, 4) the formation of the arbuscule is an asynchronous process, making it difficult to distinguish which proteins are essential in the early or late stages of AM associations. In this review we present a historical summary of how these difficulties have been overcome by technological advances in proteomics and we discuss current and future trends in the study of the proteins involved in $\mathrm{AM}$ interactions.
\end{abstract}

Keywords: Mycorrhiza; Symbiosis; Proteomics; 2DE; Mass Spectrometry

\section{INTRODUCTION}

Plants interact with a wide range of soil-borne microor-

\footnotetext{
"The authors have declared no conflict of interest.

\#Corresponding author.
}

ganisms through their roots. Some of these microorganisms behave as pathogens, causing diseases to the plant, whilst others (mutualistic symbionts) are able to support plant development and benefit in return from plant photosynthates. Among these, research has highlighted rhizobial bacteria, that favor their host plants by fixing and providing forms of nitrogen that plants can assimilate, and mycorrhizal fungi, which provide plants with mineral nutrients taken up from the soil. These fungi can be functionally divided into two main categories, ecto- and endomycorrhizas. Ectomycorrhizal fungi infiltrate the root cortex without invading plant cells and elicit plant cells responses that make nutrient exchanges possible. Endomycorrhizal fungi are, in contrast, able to cross epidermal and cortical root cells through hyphopodia and intercellular hyphae before penetration into the inner cortical cells, where they form highly branched hyphal transient structures called arbuscules. Arbuscules are assumed to be the sites where most nutrient exchanges between endomycorrhizal fungi and their host plants take place [1]. About $80 \%$ of vascular plants establish symbioses with AM fungi, forming ubiquitous interactions present in all terrestrial ecosystems, including natural and agricultural lands [2].

In natural or agricultural terrestrial ecosystems plant roots are exposed to a series of biotic and abiotic stress factors that can damage the plant and decrease survival, growth, and productivity. In AM associations, plants often benefit from increased tolerance to these stress factors. AM fungi are able to promote root growth and branching $[3,4]$, while they develop an extra-radical hyphal network that is connected to the roots and increases the depletion zone far beyond the rhizosphere [5]. This surface increase enhances the efficiency of nutrient uptake, especially phosphorus, but also other macro- and micronutrients $[1,6]$, improving plant nutritional status, particularly in poor soils. In return, the fungus is supplied with organic forms of carbon derived from the host plant photosynthesis [7-10].

AM fungi improve plant resistance to pathogen attacks, 
and damages caused to the roots seem to be compensated by an increase in the depletion zone as mentioned above [11]. Also, AM fungi grants protection against drought [12,13], salt [14-17], and heavy metal stresses [18-20]. These benefits have drawn the attention of scientists for the use of AM fungi in environmental conservation actions and sustainable agriculture practices as an alternative to the use of pesticides and chemical fertilizers [2, 21-23].

AM fungi belong to the exclusive phylum Glomeromycota [24]. They are obligate biotrophs and to date it has been impossible to obtain fungal structures like arbuscules in axenic cultures [25-27]. As the association greatly interferes with plant physiology, especially in their roots, deep changes in protein expression are expected to happen due to the association. A significant amount of work has been directed to molecular studies on different aspects of the AM symbiosis, ranging from applications to taxonomic and phylogenetic studies [28] to ecological effects of the associations. However, studies on physiological aspects need to uncover the different substances action at the post translational levels. Having that in mind, several studies of transcript and protein profile changes induced by AM associations have been performed. In this review we will discuss the methods employed to study the relations between AM fungi and their host plants by proteomic approaches. Our objective is to give an overview of the state of the art, pointing out advances and difficulties faced in the historical process.

\section{FIRST STEPS ON AM SYMBIOSIS PROTEIN STUDIES}

The first protein studies of the AM symbiosis involved extractions from colonized roots in aqueous buffers and analyses by polyacrylamide gel electrophoresis (PAGE), in search for changes in protein patterns caused by the establishment of the mycorrhizal association. For that purpose, plant tissues were homogenized in aqueous buffers our ground in liquid nitrogen before mixing with the extraction buffer at low temperature. As simple as this extraction method may be, it was shown to be fairly efficient for extracting readily soluble proteins from tissues that do not have high contents of non-proteinaceous interfering substances, like polysaccharides, lipids, or proteases. Such studies were initially performed on tobacco, onion, leek and pea plants [29,30].

Very often plant tissue samples contain proteolytic enzymes that are released into the buffer solution during cell rupture. These enzymes can cause degradation of proteins of interest in the sample, causing bands of higher molecular weight to disappear from the electrophoresis pattern, while producing other bands corresponding to artifactual smaller polypeptides that are actually fragments of larger proteins [31]. Most of the pro- teolytic enzymatic activity is reduced or eliminated at low temperatures and with the use of high-pH extraction buffer [32]. However, most often the addition of one or more protease inhibitors to the lysis buffer is required. PMSF provides such protection against enzymatic proteolysis, as shown in a subsequent work with mycorrhizal tobacco roots [33]. PMSF is an efficient inhibitor for serine proteases broadly used in protein extraction procedures from plant tissues, in concentrations that generally range between 1 and $2 \mathrm{M}$, although use of lower concentrations has been reported [34].

\section{PROTEIN SEPARATION METHODS: IMPROVING RESOLUTION}

Protein identification in earlier studies on AM interactions, based on Edman N-terminal sequencing, was very difficult because this method depends heavily on significant amount of purified proteins. This is particularly challenging in the case of the AM symbiosis since not all the root system of a plant is colonized in any given moment. Moreover, very often the $\mathrm{N}$-terminal residue is blocked in plant proteins, hindering the identification by $\mathrm{N}$-terminal Edman degradation. In this context, the first protein studies of AM interactions were limited to the use of electrophoresis-based methods to detect changes in root protein profiles induced by mycorrhization. Through this approach AM root protein profiles were first analyzed by native PAGE. Immunological assays were performed aiming to check if the differentially expressed proteins cross-reacted with antibodies raised against proteins induced by plant-root pathogen interactions, but the results were not conclusive [29]. Later, leek, onion, and pea roots were also analyzed by native PAGE, but resolution was improved by coupling the native gels to denaturing SDS gels (SDS-PAGE), which resulted in twodimensional native/SDS-PAGE gels [30]. In the same study, differentially expressed proteins were shown to be associated to chitinase, chitosanase and beta-1,3-glucanase activities, enzymes previously reported as related to plant response to pathogen attack. Native/SDS-PAGE and enzymatic assays were also used in further studies with roots of mycorrhizal pea mutants, and in addition to constitutive isoforms of chitinase, there were also one chitinase isoform induced by the presence of Glomus mosseae in the roots [33]. In tomato roots with proteins separated exclusively by native PAGE it was similarly possible to detect three constitutive chitinase isoforms and one isoform that were shown to be induced by Glomus intraradices colonization [35].

In order to improve electrophoresis resolution, protein extracts from mycorrhizal roots of red clover were fractionated by ion exchange chromatography before SDSPAGE [36]. Roots were ground in liquid nitrogen and the resulting powder was homogenized in K-phosphate 
buffer, and polyvinylpolypyrrolidone (PVPP) and ascorbic acid were added to the lysis buffer toavoid interference caused by phenolic compounds and oxidizing agents present within the sample. Compounds that could interfere with cchromatography were removed in an extra clean-up step by precipitating proteins with ammonium sulfate saturations, and salts were removed by dialysis from the precipitates. Proteins were then vacuum concentrated and ressolubilized [36]. Chromatography was used for subsequent analysis of the fractions through two independent separation methods, isoelectric focusing (IEF) and SDS-PAGE. Pre-fractioning allows for the simplification of the sample, giving clearer electrophoresis patterns and revealing the presence of proteins that are expressed in lower numbers of copies that otherwise would be masked by the presence of more abundant proteins in the sample. In addition, simpler electrophoresis patterns make it easier to detect differentially displayed proteins. This allowed the detection of protein bands responsive to AM colonization which were not detected on crude extract electrophoresis separations [36]. Differentially expressed proteins related to AM symbiosis were detected by both IEF and SDS-PAGE separations in this study, and in one of the AM-induced IEF bands superoxide dismutase activity was detected. These findings associated with previous observations of increased activity of chitinase, chitosanase and glucanase in mycorrhizal roots suggested that plant responses to AM colonization might involve the activation of defense mechanisms in at least one of the phases of the colonization process.

The procedure was repeated for studies on AM colonized pea roots [37], and the non-ionic detergent Triton $\mathrm{X}-100$ was added to the lysis buffer to improve protein solubilization. The solubilized sample was then chromatographed, fractions were vacuum concentrated, and proteins were solubilized either in Laemmli or IEF buffer. Similarly to what was observed in red clover, pea roots showed the presence of polypeptides that were induced by $\mathrm{AM}$ colonization, and these changes were detectable by IEF or SDS-PAGE separations after chromatography fractionation. No correlation could be established, however, between SOD activity induction and AM mycorhization in pea roots [37]. Finally, a purification protocol based on sequential fractioning was designed for AMcolonized pea roots allowing to identify by $\mathrm{N}$-terminal sequencing a mycorrhizal specific isoform of chitinase belonging to the chitinases Class I [38].

\section{CLEANING PROTEINS UP BY TCA/ACETONE PRECIPITATION}

Coupling IEF to SDS-PAGE protein separation procedures results in what today is considered as the conventional two-dimensional electrophoresis (2DE) gels. Technical advances accomplished along the last decade im- proved the typical resolving power of a few hundred spots in one-dimensional SDS-PAGE to up to three thousand spots in a single gel [39]. Due to this resolution power IEF/SDS-PAGE 2DE soon became the main technique used for protein separation in proteomic studies. On the other hand, this procedure is much more sensitive to interfering compounds in the samples than SDS-PAGE, and it requires protein extracts with much higher purity. An efficient and widely employed procedure to rid protein samples from interfering compounds prior to IEF is to perform protein precipitation by trichloroacetic acid (TCA) in acetone.

TCA in acetone is a very efficient precipitant and it also has high denaturing power, which immediately suppresses all proteolytic and other modifying enzyme activities that could cause artifactual changes in the sample proteins [40,41]. In addition, the method is relatively fast and simple, not involving handling of toxic compounds, though care should be taken when handling TCA because it is highly corrosive. The major drawback of TCA/acetone precipitation method is that several protein species may be lost along the process. Some proteins may not precipitate with addition of TCA/acetone and be lost when the supernatant is discarded, while others, once precipitated, may be difficult to resolubilize after the treatment [31].

TCA/acetone precipitation was used to study proteins from the shoots of mycorrhized ferns cultivated in arsenic contaminated soil. Although ferns are naturally resistant to arsenic stress and are able to accumulate this element in their fronds, clear alleviation for arsenic stress was promoted by plant mycorrhization. 2DE analysis of shoot protein extracts showed an increase in polypeptides, identified by tandem mass spectrometry coupled to liquid chromatography (LC-MS/MS) as glycolitic enzymes, which suggests that alleviation of arsenic stress is possibly related to a shift in glucose metabolism [42]. That shows that this separation technique could be useful for physiological studies, including the complex reactions to metal toxicity.

\section{PHENOL EXTRACTION OF PROTEINS}

An alternative to TCA/acetone precipitation is the extraction based on solubilization of proteins in water- or in buffer-saturated phenol [43]. In a comparative study, this method was shown to be efficient for microsomal protein extraction from plant tissues, yielding superior results when compared to direct extraction in the presence of chaotropes and detergents, including SDS, followed in this case by TCA/acetone clean-up [44]. This work was followed by others, comparing phenol extraction with different methods, including TCA/acetone precipitation, showing it as a robust technique for protein extraction from a wide range of plant organs, including highly re- 
calcitrant tissues $[41,45,46]$.

From its first use for the extraction of total proteins of tobacco roots colonized by two Glomus species, phenol extraction procedure has been employed in most studies on mycorrhizal associations. Since complete databases available for protein identification were lacking, these studies were primarily based on pattern differences between colonized and non colonized roots [25,47,48]. Ensuing investigations combined phenol extraction of proteins with 2DE and mass-spectrometry analysis, which allowed the identification of several proteins related to AM symbiosis, as well as symbiotic responses to biotic and abiotic stresses. These studies demonstrated that similarly to ferns, AM association induces a shift in glucose metabolism in Medicago truncatula, besides induction of antioxidant defenses [49]. A similar work showed that AM colonization improved M. truncatula tolerance to arsenic possibly by stimulating expression of proteins that help detoxification and metabolisation of this metal [50].

More recently, phenol extraction of proteins was shown to be very efficient also for recalcitrant tissues, such as grapevine roots [51]. In that work both G. mosseae and $G$. irregulare were shown to induce modifications in the display of 39 proteins, 25 of which were identified by matrix assisted laser desorption ionization-time of flight (MALDI-TOF) spectrometry. These identifications showed that several proteins with decreased expression in mycorrhizal plants are involved in response to hypoxia, and downregulation of proteins involved in production of free radical and antioxidant defenses was also observed [51].

Interestingly, phenol extraction of proteins was shown to be also suitable for RNA extraction, which makes possible RNA- and protein extractions from the same sample. This feature opens the possibility for synchronized proteomic and transcriptomic studies [52,53]. By using this methodology it was possible to detect that cadmiuminduced proteins in roots, were absent or less abundant in plants that were grown in presence of cadmium and $G$. intraradices-inoculated. These proteins were subjected to LC-MS/MS analysis and several were identified as proteins involved in free radical detoxification. These observations indicate that AM colonization in M. truncatula alleviates the stress caused by cadmium and that this effect can be detected by variations in protein expression levels. Analysis by Reverse Trancriptase PCR (RT-PCR) indicated direct correlation between transcript amounts of two genes and the accumulation of the correspondent proteins, which indicates that this regulation may happen at the transcription level [54]. Later, tandem mass spectrometry sequencing of proteins induced by inoculation of $M$. truncatula by either $G$. mosseae or $G$. intraradices allowed for the identification of eleven proteins of fungal origin into the root system, the first insight into fungal proteins involved in AM colonization [55].

No protein extraction method totally prevents protein losses; therefore each of them has their own drawbacks and/or advantages. For example, there is an increased number of proteins with high molecular masses in gels from phenol-extracted proteins, whereas TCA/acetone precipitation is more efficient for the extraction of proteins with molecular masses lower than $25 \mathrm{kDa}$ [31,41]. In addition, phenol is able to selectively dissolve proteins and lipids [56], allowing the separation of proteins from polysaccharides and nucleic acids, contributing to yield of highly clean protein extracts [31,41]. Therefore, although phenol extraction may lead to better quality of protein extractions in some situations, the two procedures should be considered as complementary rather than mutually exclusive methods [46].

Attempts have been made to combine the clean-up and extraction power of these two methods to obtain proteins from highly recalcitrant plant tissues. In a work on olive leaves, known for their high content in phenolic compounds, clear protein extracts were obtained from ground olive leaves through successive protein washing steps in TCA/acetone, TCA/water, acetone $80 \%$ repeatedly prior to phenol extraction, and subsequent further washings in ammonium acetate/methanol, and again in acetone [57]. This protocol was later optimized in order to save time, and it proved to be efficient for contaminant removal in a broad range of highly recalcitrant plant tissues, including woody plant parts, low-protein containing tissues or plant parts with high contents of acids, phenolic compounds, polysaccharides and lipids [58]. An independent comparative study also showed that the two combined methods could lead to better results than either phenol extraction or TCA/acetone precipitation alone [45].

Subsequent proteomics investigations on the AM interactions have had considerable increase in the coverage of mycorrhizal-related proteins with the use of the above-depicted extraction methods and 2DE. This is due to the increasing amount of available DNA sequence information for plant species and filamentous fungi in databases, and also to improvements in mass spectrometry equipments (as reviewed by Yates, Ruse et al. 2009; Cox and Mann 2011 [59,60]). However it should be underlined that at that stage most of the identified proteins were cytosolic, with very little information about membrane proteins obtained by proteomic studies.

\section{MEMBRANE PROTEINS AND ARBUSCULAR MYCORRHIZAL INTERACTIONS}

A significant part of basic research on the mycorrhizal association has focused the early events in the establishment of the symbiosis, since this would shed light not only on the functioning of this association, but also on 
other mutualistic and parasitic relationships involving plants and microbes. During the colonization process, fungal hyphopodia penetrate into the plant host root and gain access to the cortical tissue. Once they reach the inner cortical cells they are able to penetrate their cell walls and start branching within the plant cells to form the arbuscules. On its turn, the plant cell membrane does not disaggregate. Rather it invaginates, surrounding the arbuscule and forming the so-called periarbuscular membrane [61,62]. The formation of this structure is associated with a 4- to 10 fold increase in the membrane surface [7], and there is evidence of de novo synthesis of membrane components [62,63].

Most nutrient exchanges between AM fungi and their host plants are thought to happen through the periarbuscular membrane $[1,64]$. This claim is supported by several publications that report and discuss specific proteins that seem to be induced by AM association, some of them present only in colonized cells and even only in the periarbuscular membrane. Among these proteins there are active transporters of protons [65-67], phosphate [64, 68,69], nitrogen [70,71], and sugars [66,72-75]. While nutrient transfers between plants and pathogens are generally seen as unidirectional or, at least, occurring with a negative balance for the plants, nutrient exchanges between host plants and AM fungi are proved to be bidirectional, and the symbiosis may not persist if mutual benefits are not established [72,76]. In this association the mechanisms involved in carbon and mineral nutrient transfers have not yet been fully clarified $[72,74,75,77$, 78].

Surprisingly, few reports on membrane proteins based on proteomics are available for AM symbiosis. In the first of these studies microsomal proteins of tomato roots colonized by G. mosseae were analyzed and a number of spots were shown be responsive to AM mycorrhization [79].

In a subsequent study plasma membranes of tomato roots colonized by G. mosseae were isolated from endomembranes partitioned in an aqueous polyethylene glycol (PEG)/dextran two phase system [80]. This allowed detection of up to 200 reproducible spots of plasma membrane proteins resolved by 2DE, 16 of them showing differential expression related to the presence of mycorrhizal fungi. Due to the lack of a detailed database and to the identification method used, based on Edman $\mathrm{N}$-terminal sequencing, only one of these proteins was identified as an $\mathrm{AM}$ down regulated vacuolar $\mathrm{H}^{+}$-ATPase.

Medicago truncatula has been adopted as a model species for microbe-plant mutualism, and it already had more than 190,000 expression sequence tags available at 2004 [81]. The methods of phenol extraction, TCA/acetone precipitation and methanol/chloroform fractioning were compared for this plant species [82], and phenol extraction was shown to be the most efficient method for the extraction of soluble proteins for 2DE. However, the same result was not obtained for microsome-associated proteins, because high definition IEF applied to hydrophobic proteins is still not feasible. Fractioning the microsomal protein suspension in methanol/chloroform made it possible to eliminate the most hydrophobic microsomal proteins, and improved IEF resolution was obtained with mildly hydrophobic proteins. It was also observed that sample cup-loading near the anode end of the immobilized pH gradient (IPG) strip enhanced IEF resolution and was therefore more accurate than passive or active IPG strip rehydration in the presence of sample proteins (Dumas-Gaudot, unpublished results). In a subsequent work, microsomal proteins of G. mosseae colonized roots of $M$. truncatula were analyzed using an optimized protocol based on these observations. Soluble proteins were phenol-extracted and separated by $2 \mathrm{DE}$, while microsome proteins were fractionated in a methanol/chloroform two-phase system, and the mildly hydrophobic proteins were separated by 2DE whilst the strictly hydrophobic ones were separated by SDS-PAGE. Using this method, 25 microsome associated proteins, out of 36 differentially displayed spots were identified, and seven proteins were shown to be down-accumulated either upon mycorrhization or phosphate fertilization of non-inoculated plants, reinforcing the statement that AM symbiosis strongly contributes to phosphate acquisition by the plant [83].

Apart from the aqueous two-phase system PEG/dextran system mentioned above, plasma membrane proteins can also be isolated from other endomembranes present in the microsomal fraction by ultracentrifugation in a sucrose gradient. This procedure was used successfully for the study of membrane proteins of $M$. truncatula root cells that responded to $G$. intraradices colonization [84]. Membrane proteins were then analyzed by SDS-PAGE or 2DE and then further fractionation was achieved by one- or two-dimensional liquid chromatography prior to MS/MS analysis. The combination of these techniques led to the identification of 78 proteins, most of which previously described as membrane-associated proteins, including a proton efflux ATPase and a copper-binding protein [84]. Off-gel isoelectric focusing combined with isobaric tags for relative and absolute quantitation (iTRAQ) and coupled to LC-MS/MS is a promising field for the study of membrane proteins involved in AM interactions [85].

\section{RECENT ACHIEVEMENTS}

Proteomic studies have contributed to relevant advances in the understanding of biochemical mechanisms fundamental for the establishment and maintenance of the symbiotic process between plants and AM fungi. Most of 
these mechanisms have been shown to be related to defense, signaling and energetic metabolism. Yet, these findings lead to new questions. Which fungal proteins accumulate in planta during AM symbiosis? What are the differences between plant responses that promote AM symbiosis and those that avoid pathogen infection? What proteins participate specifically in each stage of the association process, from the mutual recognition by plant and fungus prior to physical contact, up to the establishment of completely functional arbuscules?

In more recent studies on AM interactions, new approaches are being used to address these questions. One of these strategies is to direct proteomic analyses towards isolated fractions of the symbiotic associations. As it is not yet possible to grow AM fungi in axenic cultures, it is not easy to isolate hyphae from plant roots for studying fungal proteins. To circumvent this problem, researchers have resorted to a culture system with two interconnected compartments is created [86]. In this system, while growth of genetically modified carrot roots is restricted to a compartment, the fungal hyphae can spread from the roots to a root free compartment, allowing the isolation of extra radical hyphae, and fungal spores Using this bi-compartimental in vitro system it was possible to settle a reference 2D map for $G$. intraradices proteins [26], and then, in a deeper study based on shotgun proteomics (GeLC-MS/MS) several fungal proteins were identified [87]. It is also possible to study internal compartments within the cell, such as nuclei, mitochondria and chloroplasts, as exemplified by several studies, but to date only one proteomic study has been performed on M. truncatula root plastids, in which 266 proteins have been identified by GeLC-MS/MS [88]. The comparison within root plastid proteins between non-inoculated and mycorrhizal roots, which demands the use of a robust MS/MS-based quantification method, is ongoing. (Daher et al., personal communication). It should be underlined that subproteomics (proteomics of cell fractions) allow simplification of protein mixtures, in addition to yield direct information about the location of the identified proteins.

Early proteomic studies on AM interactions, made it clear that the proteins responsive to AM symbiosis at the early stages of the colonization are not quite the same induced in the late stages, when the symbiosis is established and functional $[33,47,48,89,90]$. Nevertheless, it is difficult to distinguish responses for the very early stages of AM symbioses from the ones happening at the late stages, since AM colonization is an asynchronous process. After the first arbuscule is formed, new penetration events are promoted by extra-radical hyphae at the root surface, and arbuscules are continuously formed, so that all stages of arbuscule formation can be found in a single root system. Some studies have focused on the period between the inoculation moment and formation of the first arbuscules, within the first 5 to 7 days after inoculation. These studies showed that physiological responses of plant cells are detectable at protein level even before there is contact between root and fungus. By comparing three $M$. truncatula mutants, a wild type, a mycorrhizal-defective one, and a hyper-mycorrhizal one, it has been shown that plant responses previous to hyphal contact involve defense mechanisms, cell signaling, and cytoskeleton rearrangements [53,91]. Later, through the use of 2D-Differential Gel Electrophoresis (2D-DIGE) it was possible to detect the first changes in proteins within the first 6 to 12 hours after inoculation of M. truncatula with $G$. intraradices. This response involved defense mechanisms such as free radical production and antioxidant defenses, much alike what is observed when plants are inoculated with rhizobial bacteria or challenged with fungal pathogens, such defense responses seemingly decreasing with time, thus allowing the establishment of the AM symbiosis [92].

With the use of confocal microscopy techniques it was possible to understand the major cytoplasmic events that follow the contact between the hyphopodia and the roots. It was observed that root epidermal cells undergo profound changes in their architecture that involve nucleus repositioning, endoplasmic reticulum reorganization, and rearrangement of cytoskeleton elements. This rearrangement forms an internal tube called the pre-penetration apparatus that allows the entrance of the appressorium into the epidermal cell and conduces the hyphae across the cell to gain access to the outer cortical root cells [93]. These will behave the same manner conducing in turn the hyphopodium to the inner cortical cells where it will eventually penetrate and branch to form the arbuscule [94]. Thanks to the development of more sensitive and efficient MS equipment, together with the completion of $M$. truncatula genome sequencing and the use of plant mutants arrested at specific stages of the AM symbiosis, we might hope that proteins specifically involved in such peculiar events will be soon identified.

Recently, in order to analyze specific proteomic changes in arbuscule-containing cells of $G$. intraradices-colonized $M$. truncatula roots, another powerful technique has emerged that combined laser capture microdissection (LCM) and liquid chromatography-tandem mass spectrometry (LC-MS/MS) [95], allowing the identification of proteins with specific or increased expression in arbuscule-containing cells. Consistently with previous transcriptome data, the proteome of arbuscule-containing cells showed an increased number of proteins involved in lipid metabolism, most likely related to the synthesis of the periarbuscular membrane. In addition, transcriptome data of non-colonized cells of mycorrhizal roots suggest mobilization of carbon resources and their symplastic trans- 
port toward arbuscule-containing cells for the synthesis of periarbuscular membranes. This highlights the periarbuscular membrane as important carbon sink in the mycorrhizal symbiosis. The same approach is being used, in which more than 230 proteins have been identified in arbusculated cells (Dumas-Gaudot et al., unpublished data), and its combination with quantitative proteomics will provide new insights in the functioning of the AM symbiosis.

\section{CONCLUSIONS AND PERSPECTIVES}

Proteomics interfaces with and complements genomics to provide information on quantitative protein expression in any biological system. In the particular field of plantmicroorganism interactions (including the mycorrhizal symbioses), its potential is still far from being fully explored. To obtain mycorrhiza-related protein identification at a higher throughput, attempts to define more precisely both the mycorrhizal stage under study and the particular cell compartment should be continued. In this respect, recent comparative sub-cellular proteomics directed towards microsomes coupled with label-free quantitative mass spectrometry by LC-MS/MS (Abdallah et al. 2012 submitted) and plasmalemma (Aloui et al. in preparation) have proven their usefulness to identify proteins previously not reported as being expressed in AM symbiosis, together with providing information of their accumulation patterns. These two recent investigations allow for example to establish a core microsomal and a core plasmalemma of $M$. truncatula root proteome, of respectively 882 and 650 putative membrane proteins. In these two recent studies, improved membrane protein extraction protocols and advanced techniques for their fractionation, identification and quantification have been employed to detect low abundant and membrane proteins, greatly helping to expand the depth and breadth of membrane proteome changes and its fundamental role in the complex network of the AM interaction.

Comparative proteomics of several other cell compartments such as, for example, the cell wall (for improving our understanding of the recognition events accompanying the first stage of mycorrhizal infection), or the mitochondrion and/or vacuolar compartments (for decrypting parts of the regulation events during the mycorrhizal process), need to be investigated.

New insights into the complex cellular process accompanying the mycorrhizal symbiosis may also be expected from the use of more sophisticated proteomic strategies, together with the exponential increase of data in general database. So clearly, more refined proteomic tools that have emerged could be applied to the study of symbioses. Fluorescence-based DIGE allows the differential analysis of two samples concomitantly run within the same gel, circumventing reproducibility problems and image analysis [96]. Likewise, AM fungal proteomics will certainly soon benefit from the full genome sequencing of Rhizophagus irregularis formerly known as $G$. intraradices [97], opening avenues for new advances in the research of mutualistic symbioses.

\section{ACKNOWLEDGEMENTS}

This work was supported by grants from CAPES-COFECUB.

\section{REFERENCES}

[1] Smith, S.E. and Smith, F.A. (1990) Structure and function of the interfaces in biotrophic symbioses as they relate to nutrient transport. New Phytologist, 114, 1-38. doi:10.1111/j.1469-8137.1990.tb00370.x

[2] Harrier, L.A. and Watson, C.A. (2004) The potential role of arbuscular mycorrhizal (AM) fungi in the bioprotection of plants against soil-borne pathogens in organic and/ or other sustainable farming systems. Pest Management Science, 60, 149-157. doi:10.1002/ps.820

[3] Azcón-Aguilar, C. and Barea, J.M. (1997) Applying mycorrhiza biotechnology to horticulture: Significance and potentials. Scientia Horticulturae, 68, 1-24. doi:10.1016/S0304-4238(96)00954-5

[4] Berta, G., Fusconi, A. and Trotta, A. (1993) VA mycorrhizal infection and the morphology and function of root systems. Environmental and Experimental Botany, 33, 159-173. doi:10.1016/0098-8472(93)90063-L

[5] Smith, S.E. and Gianinazzipearson, V. (1988) Physiological interactions between symbionts in vesiculararbuscular mycorrhizal plants. Annual Review of Plant Physiology and Plant Molecular Biology, 39, 221-244. doi:10.1146/annurev.pp.39.060188.001253

[6] Smith, F.W., Rae, A.L. and Hawkesford, M.J. (2000) Molecular mechanisms of phosphate and sulphate transport in plants. Biochimica et Biophysica Acta-Biomembranes, 1465, 236-245.

[7] Bago, B., Donaire, J.P. and Azcón-Aguilar, C. (1997) ATPase activities of root microsomes from mycorrhizal sunflower (Helianthus annuus) and onion (Allium cepa) plants. New Phytologist, 136, 305-311. doi:10.1046/j.1469-8137.1997.00741.x

[8] Bago, B., Pfeffer, P.E. and Shachar-Hill, Y. (2000) Carbon metabolism and transport in arbuscular mycorrhizas. Plant Physiology, 124, 949-957. doi:10.1104/pp.124.3.949

[9] Bago, B., et al. (2002) Tracking metabolism and imaging transport in arbuscular mycorrhizal fungi. Metabolism and transport in AM fungi. Plant and Soil, 244, 189-197. doi:10.1023/A:1020212328955

[10] Pfeffer, P.E., et al. (1999) Carbon uptake and the metabolism and transport of lipids in an arbuscular mycorrhiza. Plant Physiology, 120, 587-598. doi:10.1104/pp.120.2.587

[11] Azcón-Aguilar, C. and Barea, J.M. (1996) Arbuscular mycorrhizas and biological control of soil-borne plant pathogens-An overview of the mechanisms involved. 
Mycorrhiza, 6, 457-464. doi:10.1007/s005720050147

[12] Abbaspour, H., et al. (2012) Tolerance of Mycorrhiza infected Pistachio (Pistacia vera L.) seedling to drought stress under glasshouse conditions. Journal of Plant Physiology, 169, 704-709. doi:10.1016/j.jplph.2012.01.014

[13] Boomsma, C.R. and Vyn, T.J. (2008) Maize drought tolerance: Potential improvements through arbuscular mycorrhizal symbiosis? Field Crops Research, 108, 1431. doi:10.1016/j.fcr.2008.03.002

[14] Giri, B., Kapoor, R. and Mukerji, K.G. (2007) Improved tolerance of Acacia nilotica to salt stress by arbuscular mycorrhiza, Glomus fasciculatum may be partly related to elevated $\mathrm{K} / \mathrm{Na}$ ratios in root and shoot tissues. Microbial Ecology, 54, 753-760. doi:10.1007/s00248-007-9239-9

[15] Langenfeld-Heyser, R., et al. (2007) Paxillus involutus mycorrhiza attenuate $\mathrm{NaCl}$-stress responses in the saltsensitive hybrid poplar Populus (X) canescens. Mycorrhiza, 17, 121-131. doi:10.1007/s00572-006-0084-3

[16] Al-Karaki, G., McMichael, B. and Zak, J. (2004) Field response of wheat to arbuscular mycorrhizal fungi and drought stress. Mycorrhiza, 14, 263-269. doi:10.1007/s00572-003-0265-2

[17] Ruiz-Lozano, J.M., et al. (2009) Exogenous ABA accentuates the differences in root hydraulic properties between mycorrhizal and non mycorrhizal maize plants through regulation of PIP aquaporins. Plant Molecular Biology, 70, 565-579. doi:10.1007/s11103-009-9492-z

[18] Hildebrandt, U., Regvar, M. and Bothe, H. (2007) Arbuscular mycorrhiza and heavy metal tolerance. Phytochemistry, 68, 139-146. doi:10.1016/j.phytochem.2006.09.023

[19] Davies, F.T., et al. (2001) Mycorrhizal fungi enhance accumulation and tolerance of chromium in sunflower (Helianthus annuus). Journal of Plant Physiology, 158, 777-786. doi:10.1078/0176-1617-00311

[20] Christie, P., Li, X.L. and Chen, B.D. (2004) Arbuscular mycorrhiza can depress translocation of zinc to shoots of host plants in soils moderately polluted with zinc. Plant and Soil, 261, 209-217. doi:10.1023/B:PLSO.0000035542.79345.1b

[21] Lecomte, J., St-Arnaud, M. and Hijri, M. (2011) Isolation and identification of soil bacteria growing at the expense of arbuscular mycorrhizal fungi. FEMS Microbiology Letters, 317, 43-51. doi:10.1111/j.1574-6968.2011.02209.X

[22] Wang, Y.Y., et al. (2008) Diversity and infectivity of arbuscular mycorrhizal fungi in agricultural soils of the Sichuan Province of mainland China. Mycorrhiza, 18, 59-68. doi:10.1007/s00572-008-0161-X

[23] Gange, A.C., Lindsay, D.E. and Ellis, L.S. (1999) Can arbuscular mycorrhizal fungi be used to control the undesirable grass Poa annua on golf courses? Journal of Applied Ecology, 36, 909-919. doi:10.1046/j.1365-2664.1999.00456.x

[24] Schüßler, A., Schwarzott, D. and Walker, C. (2001) A new fungal phylum, the Glomeromycota: Phylogeny and evolution. Mycological Research, 105, 1413-1421.

\section{doi:10.1017/S0953756201005196}

[25] Dassi, B., et al. (1999) Different polypeptide profiles from tomato roots following interactions with arbuscular mycorrhizal (Glomus mosseae) or pathogenic (Phytophthora parasitica) fungi. Symbiosis, 26, 65-77.

[26] Dumas-Gaudot, E., et al. (2004) Proteomics as a way to identify extra-radicular fungal proteins from Glomus intraradices-RiT-DNA carrot root mycorrhizas. Fems Microbiology Ecology, 48, 401-411. doi:10.1016/j.femsec.2004.02.015

[27] Ferrol, N., et al. (2004) Genomics of arbuscular mycorrhizal fungi. In: Dilip, K.A. and George, G.K., Eds., Applied Mycology and Biotechnology, Elsevier, New York, 379-403.

[28] Young, J.P.W. (2012) A molecular guide to the taxonomy of arbuscular mycorrhizal fungi. New Phytologist, 193, 823-826. doi:10.1111/j.1469-8137.2011.04029.x

[29] Dumas, E., Gianinazzi-Pearson, V. and Gianinazzi, S. (1989) Production of new soluble proteins during VA endomycorrhiza formation. Agriculture, Ecosystems and Environment, 29, 111-114. doi:10.1016/0167-8809(90)90264-E

[30] Dumas-Gaudot, E., et al. (1992) Chitinase, chitosanase and $\beta$-1,3-glucanase activities in Allium and Pisum roots colonized by Glomus species. Plant Science, 84, 17-24. doi:10.1016/0168-9452(92)90203-X

[31] Görg, A., Weiss, W. and Dunn, M.J. (2004) Current twodimensional electrophoresis technology for proteomics. Proteomics, 4, 3665-3685. doi:10.1002/pmic.200401031

[32] Hochstrasser, D.F., et al. (1988) Methods for increasing the resolution of two-dimensional protein electrophoresis. Analytical Biochemistry, 173, 424-435. doi:10.1016/0003-2697(88)90209-6

[33] Dumas-Gaudot, E., et al. (1994) Chitinase isoforms in roots of various pea genotypes infected with arbuscular mycorrhizal fungi. Plant Science, 99, 27-37. doi:10.1016/0168-9452(94)90117-1

[34] Wu, B., et al. (2011) Study of metal-containing proteins in the roots of Elsholtzia splendens using LA-ICP-MS and LC-tandem mass spectrometry. International Journal of Mass Spectrometry, 307, 85-91. doi:10.1016/j.ijms.2011.01.018

[35] Pozo, M.A.J., et al. (1999) $\beta$-1,3-Glucanase activities in tomato roots inoculated with arbuscular mycorrhizal fungi and/or Phytophthora parasitica and their possible involvement in bioprotection. Plant Science, 141, 149157. doi:10.1016/S0168-9452(98)00243-X

[36] Arines, J., Palma, J.M. and Vilariño, A. (1993) Comparison of protein patterns in non-mycorrhizal and vesicular-arbuscular mycorrhizal roots of red clover. New Phytologist, 123, 763-768. doi:10.1111/j.1469-8137.1993.tb03787.x

[37] Arines, J., et al. (1994) Protein patterns and superoxide dismutase activity in non-mycorrhizal and arbuscular mycorrhizal Pisum sativum L. plants. Plant and Soil, 166, 37-45. doi:10.1007/BF02185479

[38] Slezack, S., et al. (2001) Purification and partial amino acid sequencing of a mycorrhiza-related chitinase isoform 
from Glomus mosseae-inoculated roots of Pisum sativum L. Planta, 213, 781-787. doi:10.1007/s004250100551

[39] Maldonado, A.M., et al. (2008) Evaluation of three different protocols of protein extraction for Arabidopsis thaliana leaf proteome analysis by two-dimensional electrophoresis. Journal of Proteomics, 71, 461-472. doi:10.1016/j.jprot.2008.06.012

[40] Faurobert, M., Pelpoir, E. and Chaïb, J. (2006) Phenol extraction of proteins for proteomic studies of recalcitrant plant tissues. In: Zivy, M., Ed., Plant Proteomics. Methods and Protocols, Humana Press, Totowa, 9-14. doi:10.1385/1-59745-227-0:9

[41] Carpentier, S.C., et al. (2005) Preparation of protein extracts from recalcitrant plant tissues: An evaluation of different methods for two-dimensional gel electrophoresis analysis. Proteomics, 5, 2497-2507. doi:10.1002/pmic.200401222

[42] Bona, E., et al. (2010) Proteomic analysis of Pteris vittata fronds: Two arbuscular mycorrhizal fungi differentially modulate protein expression under arsenic contamination. Proteomics, 10, 3811-3834. doi:10.1002/pmic.200900436

[43] Schuster, A.M. and Davies, E. (1983) Ribonucleic acid and protein metabolism in pea epicotyls I. The aging process. Plant Physiology, 73, 809-816. doi:10.1104/pp.73.3.809

[44] Hurkman, W.J. and Tanaka, C.K. (1986) Solubilization of plant membrane-proteins for analysis by two-dimensional gel-electrophoresis. Plant Physiology, 81, 802-806. doi:10.1104/pp.81.3.802

[45] Saravanan, R.S. and Rose, J.K.C. (2004) A critical evaluation of sample extraction techniques for enhanced proteomic analysis of recalcitrant plant tissues. Proteomics, 4, 2522-2532. doi:10.1002/pmic.200300789

[46] Jellouli, N., et al. (2010) Evaluation of protein extraction methods for vitis vinifera leaf and root proteome analysis by two-dimensional electrophoresis. Journal of Integrative Plant Biology, 52, 933-940. doi:10.1111/j.1744-7909.2010.00973.x

[47] Simoneau, P., et al. (1994) Accumulation of new polypeptides in Ri T-DNA-transformed roots of tomato (Lycopersicon esculentum) during the development of vesicular-arbuscular mycorrhizae. Applied and Environmental Microbiology, 60, 1810-1813.

[48] Samra, A., Dumas-Gaudot, E. and Gianinazzi, S. (1997) Detection of symbiosis-related polypeptides during the early stages of the establishment of arbuscular mycorrhiza between Glomus mosseae and Pisum sativum roots. New Phytologist, 135, 711-722. doi:10.1046/j.1469-8137.1997.00695.x

[49] Aloui, A., et al. (2011) Arbuscular mycorrhizal symbiosis elicits shoot proteome changes that are modified during cadmium stress alleviation in Medicago truncatula. BMC Plant Biology, 11, 75. doi:10.1186/1471-2229-11-75

[50] Bona, E., et al. (2011) Proteomic analysis as a tool for investigating arsenic stress in Pteris vittata roots colonized or not by arbuscular mycorrhizal symbiosis. Journal of Proteomics, 74, 1338-1350. doi:10.1016/j.jprot.2011.03.027
[51] Cangahuala-Inocente, G.C., et al. (2011) Arbuscular mycorrhizal symbiosis elicits proteome responses opposite of P-starvation in $\mathrm{SO}_{4}$ grapevine rootstock upon root colonisation with two Glomus species. Mycorrhiza, 21, 473-493. doi:10.1007/s00572-010-0352-0

[52] Dumas-Gaudot, E., et al. (2004) A technical trick for studying proteomics in parallel to transcriptomics in symbiotic root-fungus interactions. Proteomics, 4, 451453. doi:10.1002/pmic.200300627

[53] Dumas-Gaudot, E., et al. (2009) Functional genomic of arbuscular mycorrhizal symbiosis: Why and how using proteomics symbiotic fungi. In: Varma, A. and Kharkwal, A.C. Eds., Springer, Berlin, 243-274.

[54] Aloui, A., et al. (2009) On the mechanisms of cadmium stress alleviation in Medicago truncatula by arbuscular mycorrhizal symbiosis: A root proteomic study. Proteomics, 9, 420-433. doi:10.1002/pmic.200800336

[55] Recorbet, G., et al. (2010) Identification of in plantaexpressed arbuscular mycorrhizal fungal proteins upon comparison of the root proteomes of Medicago truncatula colonised with two Glomus species. Fungal Genetics and Biology, 47, 608-618. doi:10.1016/j.fgb.2010.03.003

[56] Xiong, J., et al. (2011) Simultaneous isolation of DNA, RNA, and protein from Medicago truncatula L. Electrophoresis, 32, 321-330. doi:10.1002/elps.201000425

[57] Wang, W., et al. (2003) Protein extraction for twodimensional electrophoresis from olive leaf, a plant tissue containing high levels of interfering compounds. Electrophoresis, 24, 2369-2375. doi:10.1002/elps.200305500

[58] Wang, W., et al. (2006) A universal and rapid protocol for protein extraction from recalcitrant plant tissues for proteomic analysis. Electrophoresis, 27, 2782-2786. doi:10.1002/elps.200500722

[59] Cox, J. and Mann, M. (2011) Quantitative, high-resolution proteomics for data-driven systems biology. Annual Review of Biochemistry, 80, 273-299.

[60] Yates, J.R., Ruse, C.I. and Nakorchevsky, A. (2009) Proteomics by mass spectrometry: Approaches, advances and applications. Annual Review of Biomedical Engineering, 11, 49-79. doi:10.1146/annurev-bioeng-061008-124934

[61] Harrison, M.J. (9-14 August 1998) Biotrophic interfaces and nutrient transport in plant fungal symbioses. 11th International Workshop on Plant Membrane Biology, Cambridge.

[62] Gianinazzi-Pearson, V. (1996) Plant cell responses to arbuscular mycorrhizal fungi: Getting to the roots of the symbiosis. Plant Cell, 8, 1871-1883.

[63] Bonfante, P. and Perotto, S. (1995) Tansley-review No-82-Strategies of arbuscular mycorrhizal fungi when infecting host plants. New Phytologist, 130, 3-21. doi:10.1111/j.1469-8137.1995.tb01810.x

[64] Javot, H., et al. (2007) A Medicago truncatula phosphate transporter indispensable for the arbuscular mycorrhizal symbiosis. Proceedings of the National Academy of Sciences of the United States of America, 104, 1720-1725. doi:10.1073/pnas.0608136104

[65] Gianinazzi-Pearson, V., et al. (1991) Enzymatic studies 
on the metabolism of vesicular arbuscular mycorrhizas. 5 . Is $\mathrm{H}+$-atpase a component of atp-hydrolyzing enzymeactivities in plant fungus interfaces. New Phytologist, 117, 61-74. doi:10.1111/j.1469-8137.1991.tb00945.x

[66] Smith, S.E. and Read, D.J. (1997) Uptake, translocation and transfer of nutrients in mycorrhizal symbioses. Mycorrhizal Symbiosis, 2nd Edition, Academic Press, London, 379. doi:10.1016/B978-012652840-4/50015-2

[67] Ramos, A.C., et al. (2009) Arbuscular mycorrhizal fungi induce differential activation of the plasma membrane and vacuolar $\mathrm{H}^{+}$pumps in maize roots. Mycorrhiza, 19, 69-80. doi:10.1007/s00572-008-0204-3

[68] Harrison, M.J., Dewbre, G.R. and Liu, J. (2002) A phosphate transporter from Medicago truncatula involved in the acquisition of phosphate released by arbuscular mycorrhizal fungi. Plant Cell, 14, 2413-2429. doi:10.1105/tpc.004861

[69] Pumplin, N., et al. (2012) Polar localization of a symbiosis-specific phosphate transporter is mediated by a transient reorientation of secretion. Proceedings of the National Academy of Sciences of the United States of America, 109, E665-E672.

[70] Guether, M., et al. (2009) A mycorrhizal-specific ammonium transporter from Lotus japonicus acquires nitrogen released by arbuscular mycorrhizal fungi. Plant Physiology, 150, 73-83. doi:10.1104/pp.109.136390

[71] Kobae, Y., et al. (2010) Localized expression of arbuscular mycorrhiza-inducible ammonium transporters in soybean. Plant and Cell Physiology, 51, 1411-1415. doi:10.1093/pcp/pcq099

[72] Doidy, J., et al. (2012) Sugar transporters in plants and in their interactions with fungi. Trends in Plant Science, 17, 413-422. doi:10.1016/j.tplants.2012.03.009

[73] Harrison, M.J. (1997) The arbuscular mycorrhizal symbiosis: An underground association. Trends in Plant Science, 2, 54-60. doi:10.1016/S1360-1385(97)82563-0

[74] Boldt, K., et al. (2011) Photochemical processes, carbon assimilation and RNA accumulation of sucrose transporter genes in tomato arbuscular mycorrhiza. Journal of Plant Physiology, 168, 1256-1263. doi:10.1016/j.jplph.2011.01.026

[75] Helber, N., et al. (2011) A versatile monosaccharide transporter that operates in the arbuscular mycorrhizal fungus Glomus sp is crucial for the symbiotic relationship with plants. Plant Cell, 23, 3812-3823. doi:10.1105/tpc.111.089813

[76] Cameron, D.D., et al. (2008) Giving and receiving: Measuring the carbon cost of mycorrhizas in the green orchid, Goodyera repens. New Phytologist, 180, 176-184. doi:10.1111/j.1469-8137.2008.02533.x

[77] Guether, M., et al. (2011) LjLHT1.2-a mycorrhizainducible plant amino acid transporter from Lotus japonicus. Biology and Fertility of Soils, 47, 925-936. doi:10.1007/s00374-011-0596-7

[78] Talbot, J.M. and Treseder, K.K. (2010) Controls over mycorrhizal uptake of organic nitrogen. Pedobiologia, 53, 169-179. doi:10.1016/j.pedobi.2009.12.001

[79] Benabdellah, K., Azcón-Aguilar, C. and Ferrol, N. (1998)
Soluble and membrane symbiosis-related polypeptides associated with the development of arbuscular mycorrhizas in tomato (Lycopersicon esculentum). New Phytologist, 140, 135-143.

doi:10.1046/j.1469-8137.1998.00255.x

[80] Benabdellah, K., Azcon-Aguilar, C. and Ferrol, N. (2000) Alterations in the plasma membrane polypeptide pattern of tomato roots (Lycopersicon esculentum) during the development of arbuscular mycorrhiza. Journal of Experimental Botany, 51, 747-754. doi:10.1093/jexbot/51.345.747

[81] Colditz, F., et al. (2004) Proteomic approach: Identification of Medicago truncatula proteins induced in roots after infection with the pathogenic oomycete Aphanomyces euteiches. Plant Molecular Biology, 55, 109-120. doi:10.1007/s11103-004-0499-1

[82] Valot, B., Gianinazzi, S. and Eliane, D.G. (2004) Subcellular proteomic analysis of a Medicago truncatula root microsomal fraction. Phytochemistry, 65, 1721-1732. doi:10.1016/j.phytochem.2004.04.010

[83] Valot, B., et al. (2005) Identification of membraneassociated proteins regulated by the arbuscular mycorrhizal symbiosis. Plant Molecular Biology, 59, 565-580. doi:10.1007/s11103-005-8269-2

[84] Valot, B., et al. (2006) A mass spectrometric approach to identify arbuscular mycorrhiza-related proteins in root plasma membrane fractions. Proteomics, 6, S145-S155. doi:10.1002/pmic. 200500403

[85] Abdallah, C., et al. (2012) Optimization of iTRAQ labelling coupled to OFFGEL fractionation as a proteomic workflow to the analysis of microsomal proteins of Medicago truncatula roots. Proteome Science, 10, 37. doi:10.1186/1477-5956-10-37

[86] Bécard, G. and Fortin, J.A. (1988) Early events of vesicular-arbuscular mycorrhiza formation on Ri T-DNA transformed roots. New Phytologist, 108, 211-218. doi:10.1111/j.1469-8137.1988.tb03698.x

[87] Recorbet, G., et al. (2009) Fungal proteins in the extraradical phase of arbuscular mycorrhiza: A shotgun proteomic picture. New Phytologist, 181, 248-260. doi:10.1111/j.1469-8137.2008.02659.x

[88] Daher, Z., et al. (2010) Proteomic analysis of Medicago truncatula root plastids. Proteomics, 10, 2123-2137. doi:10.1002/pmic.200900345

[89] Dumas-Gaudot, E., et al. (1994) Changes in polypeptide patterns in tobacco roots colonized by two Glomus species. Mycorrhiza, 4, 215-221. doi:10.1007/BF00206783

[90] Bestel-Corre, G., et al. (2002) Proteome analysis and identification of symbiosis-related proteins from Medicago truncatula Gaertn. By two-dimensional electrophoresis and mass spectrometry. Electrophoresis, 23, 122137.

doi:10.1002/1522-2683(200201)23:1<122::AID-ELPS12 2>3.0.CO;2-4

[91] Amiour, N., et al. (2006) Mutations in DMI3 and SUNN modify the appressorium-responsive root proteome in arbuscular mycorrhiza. Molecular Plant-Microbe Interactions, 19, 988-997. doi:10.1094/MPMI-19-0988

[92] Schenkluhn, L., et al. (2010) Differential gel electro- 
phoresis (DIGE) to quantitatively monitor early symbiosis- and pathogenesis-induced changes of the Medicago truncatula root proteome. Journal of Proteomics, 73, 753-768. doi:10.1016/j.jprot.2009.10.009

[93] Genre, A., et al. (2005) Arbuscular mycorrhizal fungi elicit a novel intracellular apparatus in Medicago truncatula root epidermal cells before infection. Plant Cell, 17, 3489-3499. doi:10.1105/tpc.105.035410

[94] Genre, A., et al. (2008) Prepenetration apparatus assembly precedes and predicts the colonization patterns of arbuscular mycorrhizal fungi within the root cortex of both Medicago truncatula and Daucus carota. Plant Cell, 20, 1407-1420. doi:10.1105/tpc.108.059014

[95] Gaude, N., et al. (2012) Cell type-specific protein and transcription profiles implicate periarbuscular membrane synthesis as an important carbon sink in the mycorrhizal symbiosis. Plant Signaling and Behavior, 7, 461-464. doi:10.4161/psb.19650

[96] Ünlü, M., Morgan, M.E. and Minden, J.S. (1997) Difference gel electrophoresis: A single gel method for detecting changes in protein extracts. Electrophoresis, 18, 2071-2077. doi:10.1002/elps.1150181133

[97] Tisserant, E., et al. (2012) The transcriptome of the arbuscular mycorrhizal fungus Glomus intraradices (DAOM 197198) reveals functional tradeoffs in an obligate symbiont. New Phytologist, 193, 755-769. doi:10.1111/j.1469-8137.2011.03948.x 